\title{
David Buckingham \& Rebekah Willet (eds.) Video Cultures. Media Technology and Everyday Creativity. London: Palgrave Macmillan. 2009.
}

\section{Thomas Mosebo}

MedieKultur 2010, 49, 194-197

\section{Published by SMID | Society of Media researchers In Denmark | www.smid.dk} The online version of this text can be found open access at www.mediekultur.dk

Audiovisual communication in the form of video recording has become an essential tool within the culture of user-generated content. But has this culture just emerged through the birth of the Internet or did it develop from an earlier mediated stage? This is the starting point for David Buckingham and Rebekah Willet et al.'s anthology about the video culture, Video Cultures - Media Technology and Everyday Creativity. In the opening chapter of the book, Willett elaborates on the often-argued subject concerning the significant impact on the video culture resulting from the Internet's 'growth in access to video production' ( $p$. 1). She raises the principal issue of the diversity of video cultures and asks whether the emergence of the Internet medium has radically changed and democratised the practices of video cultures.

In order to examine this issue, the book touches upon a large miscellany of themes related to video culture. All of the contributions can easily be read as independent articles even though they are all part of the same research project. The scope of Video Cultures is a three-year research project (2005-2008) investigating amateur video making in Great Britain. Methodologically, the anthology involves several approaches including a wide-scaled survey of amateur video making, in-depth interviews with the creators of videos (in most of the chapters) and an ethnographic observational field study (Chap. 10).

Buckingham's opening article, 'A Commonplace Art' (Chap. 2), is a substantial theoretical contribution to the understanding of video cultures. He argues through Richard Chalfen's anthropological approach to domestic photography and Pierre Bourdieu's notion on pho- 
tography as social practice (p. 30) that the boundaries between amateurs and professional media producers evolve historically as a result of social circumstances and social contexts (p. 32) In that sense, Buckingham questions the technological determinism surrounding the writings on video cultures. Buckingham further advocates the transformation of amateur video production. He emphasises the transformation from a point when amateur videos were mainly concerned with the subject of domestic life towards a broader thematic focus point in the videos. Although Buckingham also argues against the celebration of the new democratisation on the basis of the participatory culture advocated by Henry Jenkins, he insists on the increasingly significant role of amateur media (p. 47). Finally, Buckingham emphasises that the connection between the process of creativity and learning is strongly tied to the culture of everyday life and to the relationship between the social world and agency.

The articles that follow in the book further explore the many different topics of video cultures. This includes Maria Pini's view on the home video mode as a narrative provider of family identities relying on the theoretic notions regarding photography proposed by Bourdieu, Sontag and Kuhn (Chap. 4). It is an insightful article, but I cannot help wondering why the article excludes considerations on any general tendencies of the home video mode and its relationship to new media platforms. In Chapter 5, Buckingham investigates the impact of video cultures within citizen journalism, including the relationship between amateurs and professionals. Buckingham's approach is a somewhat sceptical one. Through the presentation/analysis of three case studies, he argues that the general celebration of citizen journalism is exaggerated. A remaining question, nonetheless, is how the concept of citizen journalism can be regarded, which in Buckingham's case is a rather narrow definition. In the sixth chapter of the anthology, Willett explores a survey of 120 fake videos, the socalled spoof-productions. Here the argument is that producers of spoofs use the media as a social space where they can create social identities. The youth culture is also the centre of Buckingham's analysis of video cultures and self-representation in skateboarding videos in Chapter 7, in which he discusses the interchanging relationship between amateurs and professionals. Further, the skateboarding videos are self-reflexive practices, where young people use the videos as part of a learning process. Jo Henderson makes a good but also a quite obvious case in her article (Chap. 8) when she questions the free role that the BBC claims it provides to its users in the user driven video project: Video Nation. Here she discusses the institutional influence on the creative freedom of the individual user.

The anthology also demonstrates an interesting approach to the DIY-pornography culture. In Chapter 9, Pini describes the amateur pornography culture and argues like Buckingham in Chapter 5 that the celebration of Internet porn is exaggerated and far less exhibitionistic than many observers propose. Even though Pini makes a good point when downgrading the democratisation of sexual representation within new media (p. 190), the Internet's capability to democratise in the form of access and availability to pornographic content among ordinary people is still difficult to neglect, at least considering the latest 
numbers regarding online pornographic consumption. Daniel Guzner's ethnographic field study of amateur filmmaking clubs is one of the most compelling articles in the anthology. Guzner emphasises the importance of social capital as a main driving force for the survival of the film making clubs in the age of the Internet, and he further explores different club member prototypes in order to understand social identities and the hierarchy among them. In general, the article argues that social capital among the club members cannot be replicated by online activity. Finally, Willet identifies mobile cameras as a very relevant example of a performing culture in constructing online identities. The article includes some of the theories of Goffman, Chalfen as well as Giddens' term "narrative of the self" (p. 219) in order to demonstrate the social function of mobile cameras. Although her categorisations of camera phone video content appear rather incomplete, the article makes an interesting case for the use and impact of camera phones.

Chapters 4-11 elaborate and illustrate the book's principal argument and the theoretic and analytic fundament established in the initial chapters of the anthology (Chapters 2 and 3). The structure of the book is very homogeneous since the analytic fundament presented in the initial chapters is broadened in the following chapters and finally summed up in Buckingham's concluding chapter.

The notions on the interchanging relationships between amateurs and professionals are recurrent themes in the anthology, and they are explicit focal points in Chapters 3, 4, 7, 8 and 9 and thereby they support Buckingham's argument. This also includes the status of the private and the public spheres, which is a relevant subject when dealing with the domestic and the publicity cultures, as in the article on DIY pornography and Henderson's article on 'Video Nation'. Finally, the anthology also consistently focuses on the notions of creativity and learning (especially Chapters 5, 6 and 7).

As mentioned earlier, one of the major concerns in Video Cultures is the impact of the Internet and the new technologies on the emergence of amateur video cultures. The writers of this book attempt to pursue Buckingham's initial claim concerning the importance of social circumstances when they argue that amateur video cultures are not a revolutionary new phenomenon; they have existed throughout the history of the film medium. This has been a historical continuity (p. 53), since amateur skateboarding videos, domestic home videos and spoof productions etc. also existed 30 years ago. The authors argue that the most significant development of the new media platforms '[has] been to do with technologies of distribution rather than production' (p. 232).

Video Cultures leaves the reader with a solid overall impression of the ranges of audiovisual production that further intends to assure us that citizen journalism, home video modes, spoof productions and DIY pornography are basically following a line of historic continuity and that the emergence of the Internet has not radically changed the existence of video cultures. The anthology takes a position in between the advocacy of the amateur culture of democratisation as proposed by Henry Jenkins and Andrew Keen's rather cynical and disillusioned perspective on the Web 2.0 culture. It does so by arguing in favour of the 
possibilities and the significant role of the amateur video culture, but also by providing a warning against uncritical praise of a cultural revolution. Nevertheless, I would argue that the insistence on dismissing the technological impact and the general reservation towards new tendencies on the Internet as something other than a peripheral parameter prevent the book from looking ahead. It seems peculiar that the book insists on ignoring the fact that the Internet has changed the ways in which we navigate and communicate through audiovisual content, including our understanding of video cultures. This is a notion that may also influence the conclusions in this book concern the participants in the research project. They are all characterised as 'semi-professional' video producers, and $45 \%$ of the respondents in the survey were over 60 (p. 13). This precludes the possibility of concluding anything about ordinary people's use or about the average users of audiovisual communication. But then again, this was not the overall intention of the book, which in conclusion is an insightful but also somewhat controversial depiction of video cultures.

Thomas Mosebo PhD student

Department of Communication Aalborg University, Denmark tms@hum.aau.dk 